\title{
RHABDOVIRUS EN PAPAYO (Carica papaya L.) EN EL SURESTE DE MÉXICO 1
}

\author{
Enrique Noé Becerra², Elizabeth. Cárdenas ${ }^{3}$, Héctor Lozoya ${ }^{4}$, Raúl Mosqueda
}

\begin{abstract}
RESUMEN
Rhabdovirus en papayo (Carica papaya L.) en el sureste de México. En plantaciones comerciales de papaya en el Sureste de México en los estados de Chiapas, Tabasco, Oaxaca y Veracruz, se observaron incidencias de 0,1 a $10 \%$ de plantas con síntomas peculiares, éstas fueron observadas, muestreadas y estudiadas, para detectar infección viral. Los entrenudos del tallo fueron más cortos que lo normal, las hojas más cortas y coriáceas. Se observaron necrosis en hojas jóvenes, los peciolos fueron cortos y curvados con estrias gris rojizas y las flores y pequeños frutos erectos verticalmente. En tinciones negativas fueron observadas partículas de forma de bala, además de varillas e isométricas. Partículas baciliformes con una membrana perinuclear, también fueron observadas dentro de los núcleos en preparaciones ultrafinas. En preparaciones teñidas se observaron inclusiones en los núcleos del floema. La enfermedad no se transmitió mecánicamente ni por semilla. La incidencia fue más alta en el verano que en el invierno. Todas las descripciones coinciden con una infección por el Rhabdovirus necrosis apical del papayo, aunque mezclado con el potyvirus mancha anular del papayo y con unas partículas isométricas no identificadas.
\end{abstract}

\section{ABSTRACT}

Rhabdovirus in papaya (Carica papaya L.) in the southeast of Mexico. In commercial papaya plantations of the southeastern Mexican States of Chiapas, Tabasco, Oaxaca and Veracruz, 0.1 to $10 \%$ incidence of plants with peculiar symptoms were observed, sampled and studied for viral infections. Stem internodes were shorter than normal, the leaves were smaller and harder. There was necrosis in younger leaves, petioles were shorter and curved with reddish-gray stripes, and flower and small fruits were standing upright. In negative staining bullet-shaped particles were observed, as well as rod shaped and isometric ones. Bacilliform particles with a perinuclear membrane were also observed within the nucleus in ultra thin preparations, and stained preparations inclusions were present in the nucleus of the floem. The disease could not be mechanically nor seed transmitted. The incidence was higher in the summer than in the winter. All the description coincided with an infection by the papaya apical necrosis Rhabdovirus, although mixed with the papaya ringspot Potyvirus and with an isometric particle not identified.

\section{INTRODUCCION}

En México los virus reportados afectando al cultivo de papayo son: el Potyvirus de la Mancha anular del papayo (VMAP) como el principal problema (Téliz et al., 1991), Nepovirus de la Mancha anular del Tabaco (VMAT) (Rodríguez, 1994) y posiblemente el Potxvirus del Mosaico del papayo (VMP) (Rodríguez, 1994).
El grupo de los Rhabdovirus también puede afectar plantas. Estos virus son partículas baciliformes, miden de 200 a 500 nanómetros de largo y 50 a 95 de ancho, poseen una membrana nuclear que las envuelve, $y$ se acumulan en el espacio perinuclear, contienen un cordón de ARN y su transmisión es mediante insectos chupadores en forma persistente (Peters, 1981; Francki, Milne y Hatta, 1987). El primer informe de estos virus

\footnotetext{
1 Parte de tesis de doctorado en Biología en la Universidad Nacional de México (UNAM).

2 Campo experimental Cotaxtla-INIFAP, Apartado Postal 429, Veracruz, Ver. México.

3 Instituto de Fitosanidad C.P. Apartado Postal 85, Montecillos Edo. de México. México.

4 Dpto. Fitotecnia UACH Chapingo. Apartado Postal 33 Chapingo Edo. de México, México.
} 
causando daños en papayo se dio en Venezuela, a la enfermedad se le denominó Necrosis Apical del Papayo (VNAP) y se asoció a la chicharrita Empoasca papayae Omán, como su vector (Lastra y Quintero, 1981).

En Florida, Estados Unidos indicaron al Rhabdovirus de la Marchitez y necrosis del papayo (VMNP) como una nueva enfermedad, pero aparentemente distinta a la de Venezuela (Wan y Conover, 1981). Los mismos autores posteriormente determinaron que su distribución en Florida, tiene una incidencia de cero a 22,2\% (Wan y Conover, 1983).

En Cuba identificaron el Virus de la Necrosis apical del papayo por medio de microscopía electrónica y tinción de inclusiones, en las provincias de Holguín y la Habana (Mejias, Rodríguez y González, 1987).

Aunque el VMNP y VNAP se parecen en que no se transmiten mecánicamente, difieren en las medidas de las partículas; el primero mide 180-254 X 98 nanómetros y el segundo 210-230 X 80-84; VNAP es transmitido por la chicharrita E. papayae y en el caso del VMNP no se conoce el vector (Zettler y Wan, 1994).

En 1995 se observaron plantas de papayo de la variedad Maradol con síntomas diferentes a los que provoca el Virus de la Mancha Anular del Papayo (VMAP), en Veracruz, por lo que el objetivo de este trabajo fue determinar el agente causal de esta nueva enfermedad y conocer su distribución en el sureste de México.

\section{MATERIALES Y MÉTODOS}

\section{Sintomatología}

Se realizó una descripción visual de la sintomatología de las plantas de papayo variedad Maradol afectadas por la nueva enfermedad. Se colectó material foliar con diferentes síntomas, para trabajarlo posteriormente en el laboratorio.

\section{Microscopía electrónica}

Se colectaron hojas del tercio superior e intermedio de papayo variedad Maradol, con diferentes síntomas y con ellas se hicieron preparaciones con la técnica de tinción negativa. Se emplearon rejillas de cobre de 350 mallas previamente recubiertas con Formvar al 0,25\% en dicloroetano. Los contrastantes usados fueron ácido fosfotúngsico $(2 \%$ pH-6,9) y acetato de uranilo (1\%).

La metodología consistió en colocar un pedazo de tejido foliar cercano a las nervaduras, se le agregó una o dos gotas del amortiguador fosfato de potasio $0,01 \mathrm{M}$ y pH 7,0. Con la ayuda de una hoja de rasurar, se cortó en pedacitos pequeños hasta obtener un macerado, de éste se separaron los pedazos grandes, se inclinó el portaobjetos para obtener savia sin restos vegetales. Con la ayuda de una pinza fina se tomó la rejilla de cobre con la membrana hacia abajo y se posó primero sobre el macerado limpio, se dejó secar un poco y luego se colocó en el contrastante. El líquido sobrante se eliminó colocando la rejilla en papel filtro, y se guardó en cajas de Petri hasta su observación en el microscopio electrónico Modelo JEOL 100 B de la Unidad de Microscopía Electrónica del Colegio de Postgraduados.

De las muestras que se utilizaron para la observación de tinción negativa, se tomaron trocitos de cinco $\mathrm{cm}$ los cuales fueron colocados en frascos con glutaraldehído $3 \%$ en amortiguador de cacodilato de sodio al $0,2 \mathrm{M} \mathrm{pH} 6,9$, dejándose por tres horas a $4^{\circ} \mathrm{C}$. Posteriormente se seccionaron en trocitos de $0,5 \mathrm{~mm}$ y se colocaron en glutaraldehído $3 \%$ en cacodilato de sodio $0,2 \mathrm{M}$ con pH 6,9 durante dos horas a $4^{\circ} \mathrm{C}$. A continuación se realizaron tres cambios o lavados de 15 minutos cada uno, con el amortiguador cacodilato de sodio $0,2 \mathrm{M} \mathrm{pH} 6,9$. Se postfijaron en tetraóxido de osmio $1 \%$ en cacodilato de sodio $0,2 \mathrm{M} \mathrm{pH} 6,9$ durante 1,30 horas. Se lavaron tres veces durante quince minutos nuevamente con la misma solución amortiguadora y se deshidrataron en alcohol etílico 50, 70, 90 y 100\% durante 20 minutos.

Se realizaron dos cambios de resina Spurr y se llenaron cápsulas con esta misma substancia, colocándose una pieza de tejido en cada una. Se puso a polimerizar la resina por 24 horas a $60^{\circ} \mathrm{C}$. Una vez polimerizado se hicieron los cortes ultrafinos de 90 nanómetros de grosor en un ultramicrotomo OMU3 modelo 570. Los cortes se montaron en una rejilla de cobre y se observaron al microscopio electrónico.

\section{Inclusiones virales}

Se llevaron a cabo cortes de tejido afectado, de un grosor de 25 micras, con un micrótomo de congelación de $\mathrm{CO}_{2}$ American Optical modelo 880, para después realizar tinciones con los colorantes Anaranjado Calcomine y Luxol Verde Brillante y agua, Azure A y fosfato disodico $0,2 \mathrm{M}$ y Rosa de Bengala al $0,1 \%$, usando tiempos de tinción de 15 a 45 minutos. Se lavaron y se colocaron en un portaobjetos con una gota de glicerina, se cubrieron con un cubreobjetos y se observó al microscopio compuesto a un aumento de 100X utilizando aceite de inmersión. 


\section{Transmisión}

Se colectó follaje de plantas de papayo variedad Maradol con los síntomas típicos causados por Rhabdovirus sin presencia aparente de VMAP (ausencia de síntomas), el cual se maceró con el amortiguador de fosfato de sodio dibásico $0,01 \mathrm{M}$ y $\mathrm{pH} 7,0$. Se inocularon mecánicamente las siguientes plantas diferenciales: Carica papaya variedad Maradol, Nicotiana tabacum var. xanthi, Gomphrena globosa, Cucurbita pepo variedad Zuchinni, Chenopodium amaranticolor, C. quinoa, Lycopersicon esculentum, Cucumis metuliferus, Cucumis sativus y $C$. melo. De las mismas plantas de papayo se colectaron frutos y se obtuvo la semilla, ésta se lavó, eliminando la sarcotesta, se secó y sembró en dos ocasiones separadamente en charolas germinadoras (200 pozos). Para determinar si la nueva enfermedad se transmitía por semilla, se realizaron observaciones de síntomas cada siete días y se contabilizó el porciento de germinación. También se realizaron injertos de peciolos de plantas afectadas con síntomas de Rhabdovirus, por la técnica del enchapado lateral en plantas sanas de papayo de la variedad Maradol que crecían en invernadero en macetas de plástico de 20 litros.

\section{Distribución e Incidencia de plantas enfermas}

A nivel de campo se cuantificó la incidencia de la nueva enfermedad en varios municipios productores de papayo de Veracruz, Oaxaca, Chiapas y Tabasco. En dos parcelas del Campo Cotaxtla en Veracruz, se observó la secuencia de síntomas y distribución de plantas enfermas. La primera se sembró el día 18 de enero de 1995 Lote "A" en la época de bajas temperaturas; y el Lote "B" el 12 de junio en la época de altas temperaturas.

\section{RESULTADOS Y DISCUSIÓN}

\section{Sintomatología}

Las plantas de papayo observadas con síntomas peculiares en plantaciones comerciales, en general presentaron acortamiento de los entrenudos del tallo. Las hojas apicales adquirieron una apariencia de "arrepollamiento" por la disminución del tamaño de las hojas y el acortamiento de entrenudos. En el follaje más joven se presentó una necrosis de los márgenes de las hojas (Fig. 1 , a), estas adquirieron una consistencia coriácea, el

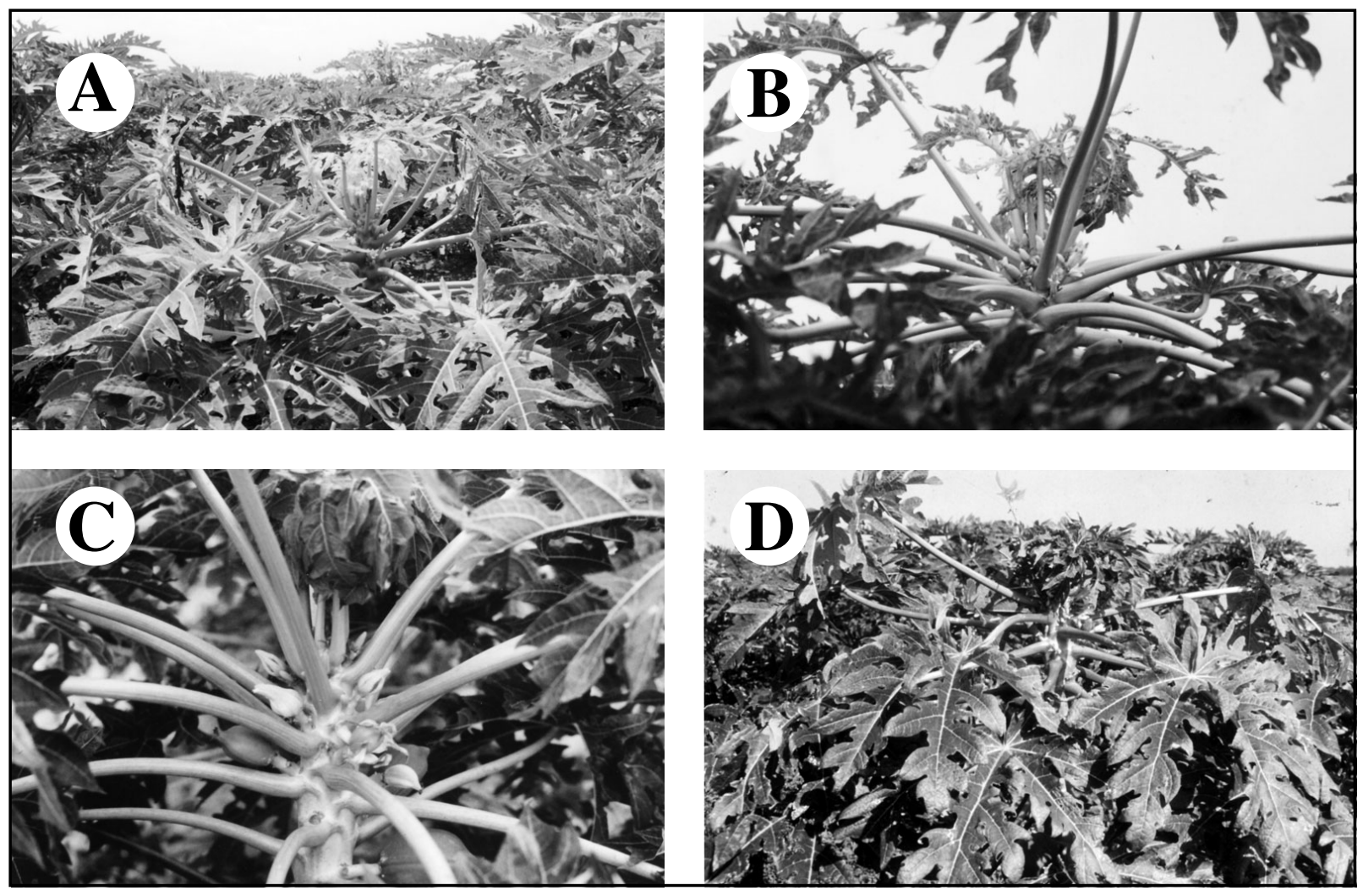

Figura 1. Síntomas peculiares observados en plantaciones comerciales de papaya.

$\mathrm{A}=$ Necrosis de los márgenes de las hojas.

$\mathrm{B}=$ Hojas coriáceas, co el tejido desprendido y nervaduras más gruesas.

$\mathrm{C}=$ Peciolos arqueados y con estrías gris rojizas.

$\mathrm{D}=$ Plantas recuperadas del daño en el mes de noviembre. 
tejido se desprendió quedando sólo las nervaduras más gruesas (Fig. 1, b) . Los peciolos se arquearon en la parte cercana a la lámina y pudieron observarse unas estrias gris-rojizas a lo largo de los mismos como costillas (Fig. 1, c).

No se manifestaron las manchas aceitosas en peciolos, tallos o frutos características del VMAP ; en las plantas en estado de floración o con frutos ya cuajados, éstas adquirieron una posición vertical (Fig 1, c) en vez de horizontal como es normal. En el mes de setiembre se presentó además una necrosis de las flores, lo que ocasionó defoliación de la planta, aunque nunca hubo muerte apical del tallo como lo informan en Venezuela y Florida (Lastra y Quintero, 1981; Wan y Conover, 1981). Incluso algunas plantas comenzaron a recuperarse (Fig. 1, d) del daño en el mes de noviembre, pero después muchas de ellas fueron infectadas por el VMAP y en ese caso se combinaron los síntomas, ya que se observaron mosaicos y deformación de los foliolos (manos de chango), presencia de manchas aceitosas en el envés de las hojas, peciolos, tallos y frutos.

\section{Microscopía electrónica}

De las muestras de hojas apicales jóvenes con necrosis en los márgenes contrastadas con ácido fosfotungsíco, se observaron partículas filamentosas flexuosas cortas y partículas esféricas. Las primeras posiblemente eran partículas incompletas del VMAP y las segundas quizás del Virus de la Mancha Anular del Tabaco (VMAT) ya que Rodríguez (1994), cita que este virus está presente en Veracruz. Esto se descartó ya que hojas de la misma planta se inocularon mecánicamente en plantas de tabaco (Nicotiana tabacum variedad xanthi) sin que estas llegaran a infectarse. Fariñas (1990) menciona la presencia de partículas esféricas en extractos purificados a partir de hojas con síntomas parecidos a los que causa el VMAP, pero sin llegar a identificarlo.

En las preparaciones hechas con acetato de uranilo y savia de síntomas con líneas grises-rojizas en peciolos, necrosis de tejido en hojas jóvenes, desprendimiento de tejido en hojas maduras donde quedan sólo restos de tejido alrededor de las nervaduras gruesas (de esta parte se tomó material para la tinción), con abolsamientos y mosaico, se pudieron observar solamente partículas de forma de bala. Lo cual está de acuerdo con Cambell y Lin (1972) quienes citan que con la tinción de acetato de uranilo los Rhabdovirus quedan con esa forma.

En las muestras de follaje con los síntomas típicos del VMAP combinados con los de Rrhabdovirus, con ácido fosfotúngsico, se observaron varillas filiformes flexuosas completas y partidas, además de partículas en forma de bala (Fig. 2, a). Esto concuerda con Cambell y Lin
(1972) quienes mencionan que el Virus del Amarillamiento necrótico del brocoli en tinción con fosfotungstato de potasio, las partículas de este virus adquieren la forma de bala (debido a un artificio de la tinción) y con acetato de uranilo son de forma baciliforme. Por otro lado Francki, Milne y Hatta (1987) mencionan que en preparaciones teñidas negativamente a menudo las partículas de los Rhabdovirus aparecen de forma de bala, pero ahora es generalmente aceptado que las partículas de este grupo son de naturaleza baciliforme. En la misma preparación también se observaron partículas esféricas.

\section{Secciones ultrafinas}

Al observar los cortes al microscopio electrónico se encontró que había dentro del núcleo de las células del floema, presencia de partículas en forma de bacilo rodeadas por una membrana y (Fig. 2, b).

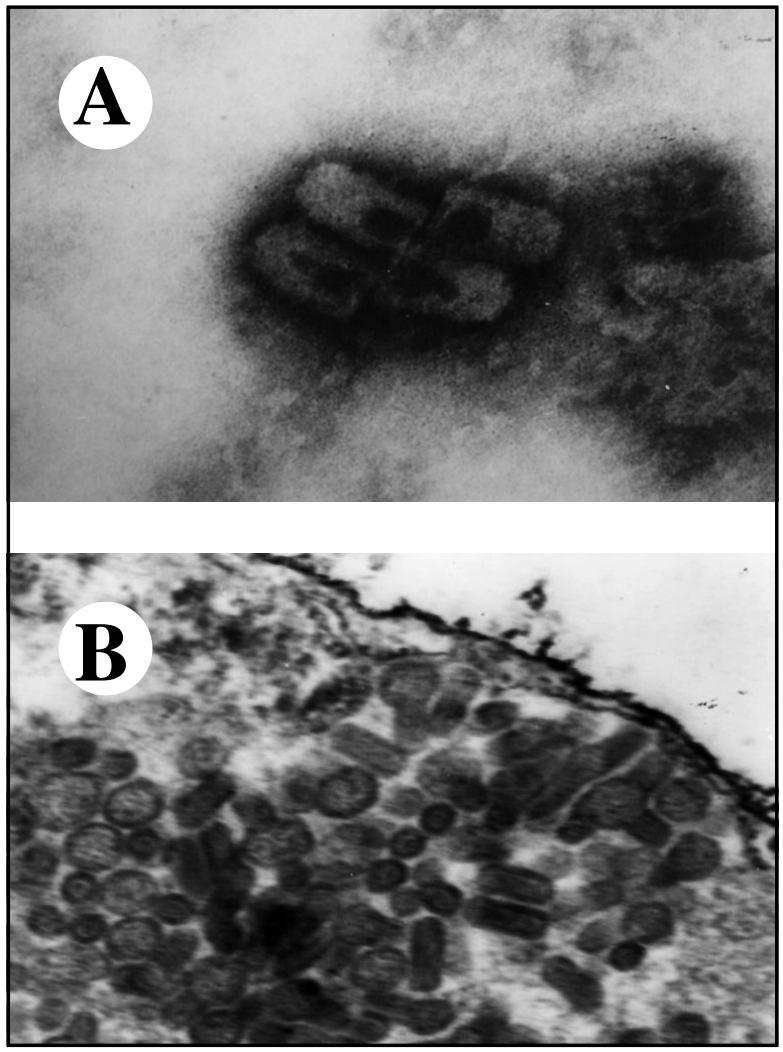

Figura 2. Muestras de follaje con síntomas típicos del VMAP combinados con los del Rhabdovirus con ácido fosfotúngsico.

$\mathrm{A}=$ Partículas en forma de bala.

$\mathrm{B}=$ Partículas en forma de bacilo rodeadas por una membrana. 


\section{Tinción de inclusiones}

En la tinción del material (cortes al micrótomo de congelación) con la técnica de Christie (Christie y Edwardson, 1977) se observó el nucléolo de color verde dentro del núcleo, y cerca de este inclusiones de tipo granuloso y vacuolar del mismo color con la tinción del colorante Anaranjado Calcomine y Luxol Verde Brillante. Con el Azure A se observaron inclusiones dentro del núcleo de color azul intenso. Con la tinción de Rosa de Bengala los núcleos toman una coloración rosa, al igual que las inclusiones y además fueron de tipo granulosa. Mejias, Rodríguez y González, (1987) mencionan que con la técnica de tinción de Rosa de Bengala las inclusiones son bastante grandes como para observarse al microscopio óptico, pero no citan la forma de las mismas. En todos los casos las inclusiones se detectaron en las células cercanas a los haces vasculares.

\section{Transmisión}

Las plantas inoculadas mecánicamente no se infectaron, lo anterior concuerda con Zettler y Wan (1994) quienes mencionan que este virus de papayo no se transmite por este medio. Con lo que respecta a la trasmisión por semilla, tampoco se detectaron plantas con síntomas de la enfermedad y los porcentajes de semillas que germinaron en la prueba de viabilidad estuvieron entre 40 y $47 \%$. En el caso del injerto de peciolo no se logró transmitir la enfermedad en cuatro intentos.

\section{Distribución e incidencia de plantas enfermas}

En los recorridos por algunos municipios de Veracruz (Paso de Ovejas, Puente Nacional, Alamo, Piedras
Negras, Cotaxtla, Medellín de Bravo, Jamapa y Actopan) se observó la presencia de la enfermedad tanto en la variedad criolla Cera como en Maradol. En Oaxaca (en los municipios de Acatlán de Pérez Figueroa y Tetitlán) en Maradol, para Chiapas sólo se detectó en el municipio de Suchiate en la variedad Maradol y en Tabasco (en los municipios de Cunduácan, Cárdenas y Reforma) en la variedad Maradol y criolla Mamey (Cuadro 1). Para confirmar si era la misma enfermedad, sólo en el caso del municipio de Medellín de Bravo se observaron muestras al microscopio electrónico, las demás fueron con base en la sintomatología. Los porcentajes de incidencia fueron bajos $(0,1-10 \%)$ en Veracruz en comparación con los del Virus de la Mancha Anular del Papayo (100\%), esto concuerda con el trabajo de Wan y Conover (1983) en Florida. En Oaxaca se presentó más incidencia del Rhabdovirus al igual que en Chiapas y Tabasco, en éstos la presencia del VMAP sólo se manifiestó con pocas manchas aceitosas en frutos y algunos peciolos, sin mostrar los típicos mosaicos en el follaje. En las parcelas del Campo Cotaxtla se presentaron las sintomatologías a partir del verano (Lote "A") con disminución en invierno, algunas plantas se recuperaron, algunas murieron y en otras se combinan con los síntomas que causa el Virus de la Mancha Anular del Papayo. A diferencia de lo que ocurre en Florida donde primero se presenta el VMAP, en las plantaciones de papayo y luego aparece el Rhabdovirus. En nuestro caso las dos enfermedades ocurrieron al mismo tiempo; sin embargo el VMAP es el que enmascara al Rhabdovirus. Aunque no se mencionan las temperaturas en los otros países. En México se presentó con temperaturas máximas de $35^{\circ} \mathrm{C}$, medias de $28^{\circ} \mathrm{C}$ y mínimas de $20^{\circ} \mathrm{C}$, por lo que es probable que estas temperaturas estén entre el rango del insecto vector

Cuadro 1. Presencia de plantas con síntomas de rhabdovirus en diferentes estados y municipios del sureste de México. 199_.

\begin{tabular}{llccc}
\hline Estado & \multicolumn{1}{c}{ Municipio } & $\begin{array}{c}\text { Presencia } \\
\text { VMAP }\end{array}$ & $\begin{array}{c}\text { Presencia } \\
\text { Rhabdovirus }\end{array}$ & Variedad \\
\hline Chiapas & Mapastepec & $\mathrm{X}$ & & Maradol \\
& Huehuetan & $\mathrm{X}$ & $\mathrm{M}$ & Maradol \\
& Suchiate & & $\mathrm{X}$ & Mamey \\
Tabasco & Cunduacan & & $\mathrm{X}$ & Maradol \\
& Cardenas & $\mathrm{X}$ & $\mathrm{X}$ & Mamey \\
& Reforma & $\mathrm{X}$ & & Mamey \\
& Del Centro & $\mathrm{X}$ & $\mathrm{X}$ & Maradol \\
Oaxaca & $\mathrm{X}$ & $\mathrm{X}$ & Maradol \\
& Acatlan De Pérez Figueroa & $\mathrm{X}$ & $\mathrm{X}$ & Cera y Maradol \\
Veracruz & $\mathrm{X}$ & $\mathrm{X}$ & Cera y Maradol \\
& Tetitlan & $\mathrm{X}$ & $\mathrm{X}$ & Cera y Maradol \\
& Paso De Ovejas & $\mathrm{X}$ & $\mathrm{X}$ & Maradol \\
& Puente Nacional & $\mathrm{X}$ & $\mathrm{X}$ & Cera y Maradol \\
& Alamo & $\mathrm{X}$ & $\mathrm{X}$ & Maradol \\
& Piedras Negras & $\mathrm{X}$ & $\mathrm{X}$ & Maradol \\
& Cotaxtla & $\mathrm{X}$ & $\mathrm{X}$ & Cera y Maradol \\
\hline
\end{tabular}


encargado de la diseminación del Rhabdovirus. Para otras enfermedades de este tipo se han informado a chicharritas, áfidos, ácaros y chinches del orden Hemiptera (Peters, 1981) .

Las primeras plantas enfermas en el Lote " $A$ " (siembra de invierno) se detectaron en el mes de agosto, el mayor número de plantas enfermas sin embargo fue en setiembre (26) y posteriormente van disminuyendo. Al llevar a cabo una incisión en las manchas aceitosas, la savia fluyó libremente, lo que descarta la presencia de la enfermedad Bunchy Top causada por organismos tipo Mycoplasmas (Story y Halliwell, 1969; Cook, 1972). En el Lote "B" las primeras plantas enfermas se presentaron también en el mes de agosto, pero se comenzaron a contabilizar a partir de octubre, la infección provino del lote "A" que se encontraba aproximadamente a 100 metros.

Las infecciones más altas se dieron en el mes de octubre (39) y disminuyeron paulatinamente. En ambos casos no influyó tanto la fecha de siembra, sino la temporada ya que las infecciones comenzaron a partir de agosto y la temperatura media en que se presentaron las máximas infecciones fue de $29^{\circ} \mathrm{C}$ y después de altas precipitaciones.

Se revisaron las plantas para detectar posibles insectos vectores, pero sólo se observaron 10 a 15 mosquitas blancas y una a dos chicharritas por planta, estas se colectaron y mandaron a identificar al Centro Nacional de Referencia de Sanidad Vegetal en la Ciudad de México, dando como resultado la presencia de los géneros Tettigonia prolixa, T. occatoria, Tettigonia sp., Agallia modesta, A. lingula de la Familia Cicadellidae y el género Sogata sp., de la familia Delphacidae. Aunque Lastra y Quintero (1981) mencionan a la chicharrita Empoasca papayae como el vector de la enfermedad. Los resultados de este trabajo concuerdan con los de Zettler y Wan (1994) ya que al igual que en Florida no se encontró a $E$. papayae asociada al cultivo en los muestreos. Las plantas enfermas estaban en grupos o tendían a agruparse, lo que puede indicar que el vector no tenía mucha capacidad de vuelo.

Los síntomas concuerdan con los de Florida y Venezuela (Wan y Conover, 1981; Lastra y Quintero, 1981), además de que en esos sitios se menciona que la enfermedad se presenta en verano, pero es más agresiva durante los meses de invierno, como en México.

\section{CONCLUSIONES}

Se reporta un nuevo virus (Virus de la Necrosis apical del papayo) afectando el cultivo de papayo en México. Las incidencias de este virus aún son bajas en los estados de Chiapas, Veracruz, Oaxaca y Tabasco.

\section{LITERATURA CITADA}

CAMBELL, R.N.; LIN, M.T. 1972. Broccoli necrotic yellows virus. Descriptions of plant viruses No.115. Commonwealth mycological institute. Association of applied biologist. Kew Surrey, England. 4 p.

COOK, A.A. 1972. Virus diseases of papaya. Fla. Agric. Exp. Stn. Tech. Bull. 750. 19 p.

CHRISTIE, J.R.; EDWARDSON, J.R. 1977. Light and electron microscopy of plant virus inclusions. Fla. Agr. Expt. Sta. Monogr. Ser. 9. 150 p.

EDWARDSON, J.R.; CHRISTIE, R.G. 1978. Use of virus-induced inclusions in classification and diagnosis. Ann. Rev. Phytopathol. 16: 31-55.

FARIÑAS, M.E. 1990. Principales plagas y enfermedades que afectan el cultivo de papaya en Cuba. CIDA.Cd. de la Habana. 32 p.

FRANCKI, R.I.B.; MILNE, R.G.; HATTA, T. 1987. Atlas of plant viruses. Vol I. C.R.C. Press. pp. 73-100.

LASTRA, R.; QUINTERO, E. 1981. Papaya apical necrosis, a new disease associated with a rhabdovirus. Plant Disease. 65: 439-440.

MEJÍAS, Y.; RODRÍGUEZ, D.;GONZÁLEZ, G. 1987. Rhabodovirus asociado a síntomas de necrosis apical en fruta bomba Carica papaya en Cuba. Cienc. Tec. Agric. Protección de plantas 10:57-62.

PETERS, D. 1981. Plant Rhabdovirus group. Descriptions of Plant Viruses No. 244. Commonwealth mycological institute. Association of applied biologist. Kew Surrey, England. 6 p.

RODRÍGUEZ, E.J.G. 1994. Distribución de las virosis del papayo en México. Tesis Mag. Sc. Colegio de Postgraduados. Montecillos, Edo. de México. 84 p.

STORY, G.E.; HALLIWELL, R.S. 1969. Association of a mycoplasmalike organism with the bunchy top disease of papaya. Phytopathology 59: 1336-1337.

TÉLIZ, O.D.; MORA, A.G.; NIETO, A.D.; GONSALVES, D.; GARCIA, E.; MATHEIS, L.; AVILA, C. 1991. La mancha anular del papayo en México. Revista Mexicana de Fitopatología. 9: 64-68.

WAN, S.H.; CONOVER, R.A. 1981. A Rhabdovirus associated with a new disease of Florida papayas. Proc. Fla. State Hort. Soc. 94: 318-321.

WAN, S.H.; CONOVER, R.A. 1983. Incidence and distribution of papaya viruses in Southern Florida. Plant Disease. 67: 353-356.

ZETTLER F.W.; WAN, S.H. 1994. Papaya diseases caused by virus. In: Compendium of tropical fruit diseases. (Eds.) Ploetz, R.C., Zentmeyer, G.A., Nishijima, W.T., Rohrbach, K.G. and Ohr, H.D. APS, St. Paul Minnesota, USA. pp. 66-68. 